\title{
DUPLICATION OF BOWEL PRESENTING AS CHRONIC ABDOMINAL PAIN
}

Suresh S. Karlatti ${ }^{1}$, I. B. Havannavar², Uma R. B ${ }^{3}$

\section{HOW TO CITE THIS ARTICLE:}

Suresh S. Karlatti' ${ }^{1}$ I. B. Havannavar², Uma R. B33. "Duplication of Bowel Presenting as Chronic Abdominal Pain". Journal of Evolution of Medical and Dental Sciences 2014; Vol. 3, Issue 50, October 06; Page: 11853-11855, DOI: $10.14260 /$ jemds $/ 2014 / 3560$

ABSTRACT: Duplication of bowel represents one of many congenital abnormalities of the gastrointestinal tract. It is a not uncommon cause of acute abdominal pain but remains a consideration in the pediatric population. It is well known that exploratory laparotomy is undertaken in pediatric patients. But in adults it will be difficult to diagnose this as the cause of chronic abdominal pain. We present the case of a patient who was admitted to hospital several times for recurrent abdominal pain in whom we eventually diagnosed intestinal duplication.

KEYWORDS: Bowel duplication, Congenital anomaly.

CASE REPORT: A 23-year-old man presented to the emergency department at the District Hospital Belgaum, attached to Belgaum Institute of Medical Sciences, Belgaum with a history of acute onset of cramping per umbilical pain and vomiting. His medical history included multiple admissions over a 6year period for similar symptoms. Physical examination revealed mild abdominal tenderness but no peritonitis. Soon after admission, his acute abdominal pain resolved.

An ultra sonological report of abdomen revealed a multiloculated cystic mass, suggesting a mesenteric cyst. In view of chronic pain in the abdomen, we obtained consent for exploratory laparotomy. The procedure revealed an ileal duplication 38-cm long with a cystic dilatation that had adhesions to the transverse colon (Fig.1). The base of the cyst was fibrotic, suggesting that recurrent obstruction at this level resulted in the patient's periodic episodes of abdominal pain. We resected the cyst and the parallel segment of small bowel and conducted a primary anastomosis. The patient had an uneventful postoperative period.

DISCUSSION: Gross and colleagues ${ }^{1}$ first defined intestinal duplication as "spherical or tubular structures that possess a well-developed smooth muscle layer and are lined with a mucous membrane; they are found at any level from tongue to anus and usually are intimately attached to some portion of the alimentary tube." One large study ${ }^{2}$ suggests that most duplications are intraabdominal and of these, ileal and ileocecal duplications are the most common.

Clinical presentation is similar to that in our patient's case and includes recurrent abdominal pain, vomiting, abdominal distension, gastrointestinal hemorrhage and sometimes peritonitis if a peptic ulcer perforation occurs in the duplicated segment with ectopic gastric mucosa or in the adjacent normal bowel.3,4

The duplication can be the lead point in intussusception ${ }^{2,4}$ or the site of volvulus. ${ }^{2}$ Pre-natal ultrasound or ultrasound at the time of clinical presentation may lead to the diagnosis of these benign lesions. Differentiation from mesenteric cysts can sometimes be made during that initial ultrasound based on the thinner nature of the intestinal wall. Preoperative diagnosis is more commonly made with intestinal duplications of foregut than of mid gut or hindgut origin. ${ }^{4}$

The universally accepted management of this condition is surgical intervention, and the outcome is good in these patients who do not have any other congenital abnormality. 
Recommendations for surgical management are based on the age and condition of the patient; the location, nature and extent of the lesion; and the number of anatomic locations involved. Total excision is generally preferred if possible and will usually involve resection of the involved normal bowel, 5 as in our patient's case.

This approach is not always feasible, as in patients in whom resection will result in short bowel syndrome or the duplicated segment involves vital structures like the duodenum in close proximity to the common bile duct. In these instances, partial resection, marsupialization or internal drainage may be performed. Blunt dissection without resection or anastomosis of the normal adjacent bowel has been described. ${ }^{4}$ As a majority of these lesions share a common wall, the involved risks include de vascularization of the adjacent bowel if the arterial supply is intimately shared and iatrogenic bowel wall injury.

The presence of heterotopic gastric mucosa negates internal drainage as adjacent non gastric mucosa is at risk for peptic ulceration, hemorrhage and perforation, and mucosal stripping may be performed if resection is not advised. ${ }^{4}$ Reports of the long-term sequelae of untreated intestinal duplications are not numerous in the literature as most patients present with symptoms in childhood. Adult patients present with similar symptoms of recurrent abdominal pain, intestinal obstruction or hemorrhage, or the lesion may be found incidentally at autopsy. Rarely, cancer has been described and is more common in duplications of the large bowel; however, lesions of the ileum may also be involved. ${ }^{5}$

\section{REFERENCES:}

1. Gross RE, Holcomb GH, Farber S. Duplications of the alimentary tract. Pediatrics. 1952; 9: 449-68.

2. Basu R, Forshall I, Rickham PP. Duplication of the alimentary tract. Br J Surg. 1960; 47: 477-84.

3. Iyer CP, Manhour GH. Duplications of the alimentary tract in infants and children. J Pediatr Surg.1995; 30: 1267-70.

4. Balen EM. Giant jejunoileal duplication: prenatal diagnosis and complete excision without intestinal resection. J Pediatr Surg. 1993; 28: 1586-8.

5. Orr MM, Edwards AJ. Neoplastic changes in duplications of the alimentary tract. Br J Surg.1975; 32: $269-74$.

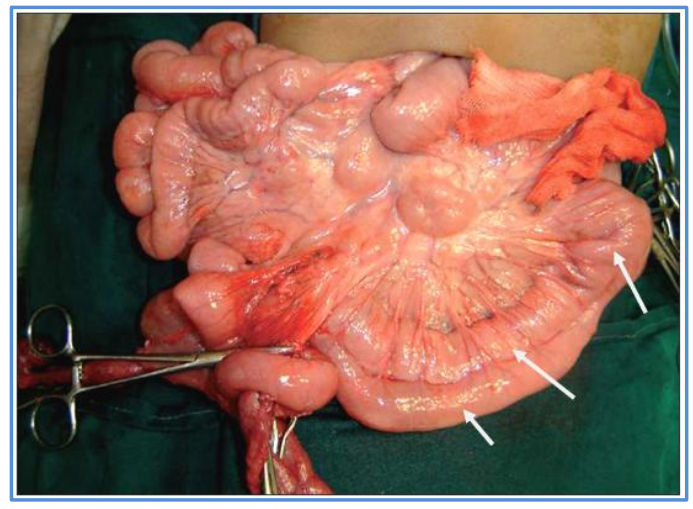

Fig. 1: Proximal Arrow showing original bowel

$\&$ next two arrows showing duplication of bowel 


\section{CASE REPORT}

\section{AUTHORS:}

1. Suresh S. Karlatti

2. I. B. Havannavar

3. Uma R. B.

\section{PARTICULARS OF CONTRIBUTORS:}

1. Assistant Professor, Department of Surgery, Belgaum Institute of Medical Sciences, Belgaum.

2. Professor \& HOD, Department of Surgery, Belgaum Institute of Medical Sciences, Belgaum.

3. Assistant Professor, Department of Anaesthesiology, Belgaum Institute of Medical Sciences, Belgaum.

\section{NAME ADDRESS EMAIL ID OF THE}

\section{CORRESPONDING AUTHOR:}

Dr. Suresh S. Karlatti,

Assistant Professor,

Department of Surgery,

Belgaum Institute of Medical Sciences,

Belgaum-590001.

Email: Suresh_karlatti@rediffmail.com

Date of Submission: 12/09/2014.

Date of Peer Review: 13/09/2014.

Date of Acceptance: 27/09/2014.

Date of Publishing: 06/10/2014. 